\title{
Myosin VI is associated with secretory granules and is present in the nucleus in adrenal medulla chromaffin cells
}

\author{
Łukasz Majewski^, Magdalena Sobczak` and Maria Jolanta Rędowicz ${ }^{\bowtie}$ \\ Department of Biochemistry, Nencki Institute of Experimental Biology, Warszawa, Poland
}

\begin{abstract}
Myosin VI (MVI) is the only known myosin walking towards minus end of actin filaments. Here, MVI, but not myosins IB or IIB, was detected in chromaffin granules isolated from bovine medulla and found to be tightly associated with the granule apical surface. MVI also localized to secretory granules within rat pheochromocytoma PC12 cells as well as to the Golgi apparatus, endoplasmic reticulum and clathrin-coated pits. Notably, it was also found in the nucleus. RT-PCR revealed that MVI splice variants with a large insert (LI), characteristic of polarized cells, were barely detectable in PC12 cells, whereas variants with a small insert (SI) were the major isoforms. The presented data indicate that MVI in adrenal medulla cells is engaged in secretory vesicle trafficking within the cytoplasm and possibly also involved in transport within the nucleus.
\end{abstract}

Keywords: myosin VI, chromaffin granules, PC12 cells, Golgi apparatus

Received: 04 December, 2009; revised: 04 January, 2010; accepted: 31 January, 2010; available on-line: 02 March, 2010

\section{INTRODUCTION}

The highly specialized chromaffin cells of adrenal medulla contain secretory organelles (chromaffin granules) which store catecholamines, nucleotides and several neuropeptides. Chromaffin granules are stored in two major cytoplasmic pools, the reserve and the release-ready ones (Hook \& Metz-Boutigue, 2002; Trifaro, 2002), which are separated by a barrier formed by a dense actin filament network that in response to cell stimulation undergoes precisely regulated depolymerization thus enabling a shift of the granules from the reserve to the releaseready pool, and the secretion process (Bader et al., 2002). Myosins, ATP- and actin-dependent molecular motors, have not only been detected in chromaffin cells but also found to be involved in granule trafficking (Wagner et al., 1992; Rose et al., 2002; Wu et al., 2002).

Myosins form a structurally and functionally diverse superfamily that consists of more than 20 distinct families (Richards \& Cavalier-Smith, 2005; Foth et al., 2006). The classic two-headed myosins of family II are called conventional myosins, while the other families are referred to as unconventional ones. Several myosin isoforms, including myosins IA, IIA, IIB, VA and VI, have been detected in chromaffin cells (Wagner et al., 1992; Rose et al., 2002; Wu et al., 2002; Rudolph et al., 2003; Neco et al., 2004). Myosin VA has been shown to be involved in the translocation of granules towards the plasma membrane, and lack of the functional protein leads to decrease of noradrenaline release and strong reduction of granules' motility within the actin cortex (Rose et al., 2003; Rudolph et al., 2003). Myosin IIB is not associated with chromaffin granules but its indirect involvement in the vesicles transport has been postulated (Rose et al., 2003).

Myosin VI, one of the unconventional myosins, consists of a $140-\mathrm{kDa}$ heavy chain containing one IQ motif to which calmodulin binds. Its C-terminal tail contains a globular domain essential for cargo binding and/or interaction with binding partners (see Sweeney \& Houdusse, 2007; Buss \& Kendrick-Jones, 2008). Four splice variants of myosin VI can be expressed in mammalian cells, differing in the presence of insertions within the tail domain that seem to determine its localization and function (Aschenbrenner et al., 2003; Au et al., 2007). The C-terminal globular domain binds to membraneassociated proteins (termed myosin VI-binding-partners), such as Dab2 in small intestine epithelial cells (Morris et al., 2002), SAP97 in the central nervous system neurons (Wu et al., 2002), GIPC in retinal pigment epithelium (Aschenbrenner et al., 2003), or optineurin (Spudich et al., 2007). It has been recently shown that a positively charged region of the globular tail binds specifically to $\mathrm{PIP}_{2}$-containing liposomes (Spudich et al., 2007).

Myosin VI seems to be a processive motor involved in vesicular transport (Mermall et al., 1994; Buss et al., 2002). However, unlike other myosins it moves towards the minus (pointed) end of actin filaments (Wells et al., 1999). This implies that it may play a different role than other myosins engaged in the same processes. Mutations within the myosin VI gene lead to deafness in mice and humans (Redowicz 2002). Other symptoms in mice include head tossing and hyperactivity, and in humans gradually developing blindness, craniofacial aberrations and hypertrophic cardiomyopathy. Several morphological defects have been observed in various cells derived from the deaf Snell's waltzer mice (Warner et al., 2003; Osterweil et al., 2005; Ameen \& Apodaca, 2007).

Both functional studies and its cellular localization indicate that myosin VI plays a major role in endocytic traffic pathways as well as in cell motility (see Sweeney \& Houdusse, 2007; Buss \& Kendrick-Jones, 2008). It has been demonstrated that in hippocampal neurons myosin VI is involved in neutrotransmission dependent on brain-derived neurotrophic factor (BDNF) and its receptor TrkB (Yano et al., 2006). So far, it is not clear wheth-

\footnotetext{
$\triangle$ e-mail: j.redowicz@nencki.gov.pl

ॠThese authors contributed equally to the manuscript

Abbreviations: BSA, bovine serum albumin; DAPI, 4,6-diamidino-2phenylindole; $\mathrm{D} \beta \mathrm{H}$, dopamine $\beta$-hydroxylase; EEA1, early endosome antigen 1; LI, large insert; PBS, phosphate-buffered saline; $\mathrm{PIP}_{2}$, phosphatidylinositol 4,5-bisphosphate; PMSF, phenylmethylsulfonyl fluoride; SI, small insert.
} 
er this myosin isoform works as a transporting motor or as an anchor linking the vesicles and/or plasma membrane proteins to the actin cytoskeleton, responsible for the maintenance of integrity of the cytoskeleton.

Recently, it has been shown that myosin VI is associated with the RNA polymerase transcription machinery, thus implicating an involvement of myosin VI in activation of gene expression (Vreugde et al., 2006).

To address the role of myosin VI in secretory cells, we tested its localization and expression pattern in PC12 cells derived from a rat adrenal medulla tumor, which serve as a cell model to study neuronal and endocrine secretion (Martin \& Grishanin, 2003).

\section{MATERIALS AND METHODS}

Cell culture. PC12 cells (American Cell Culture Collection, USA) were cultured in RPMI 1640 or DMEM media supplemented with $10 \%$ heat-inactivated horse serum and $5 \%$ fetal bovine serum at $37^{\circ} \mathrm{C}$ under $5 \% \mathrm{CO}_{2}$, as described in (Green \& Tischler, 1976). Primary culture of chromaffin cells was derived from bovine adrenal medulla as recommended by (Nagy et al., 2002). Briefly, chromaffin cells were isolated from adrenal glands by collagenase treatment and purified by centrifugation without the use of Percoll gradient. Cells were then suspended in DMEM medium supplemented with penicillin/streptomycin (40000 U/L and $40 \mathrm{mg} / \mathrm{L}$; Sigma) and $10 \mathrm{ml} / \mathrm{L}$ insulin-transferrin-selenium-X (Invitrogen), and cultured at $37^{\circ} \mathrm{C}$ under $5 \% \mathrm{CO}_{2}$.

Chromaffin granule preparation. The isolation was performed at $4{ }^{\circ} \mathrm{C}$, generally according to a procedure described by Brocklehurst and Pollard (1990). Bovine adrenal glands were collected at the local slaughterhouse and transported on ice in buffer A (0.3 M sucrose, 1 $\mathrm{mM}$ EGTA and $5 \mathrm{mM}$ Hepes, $\mathrm{pH}$ 7.3). Medullae were cut into pieces, homogenized in 10 vol. of buffer $\mathrm{A}$ in a teflon-glass homogenizer, filtered through surgical gauze and centrifuged at $800 \times g$ for $15 \mathrm{~min}$. The pellet containing membranes was resuspended in buffer $A$ and centrifuged again at $20000 \times \mathrm{g}$ for $30 \mathrm{~min}$ to separate mitochondrial fraction. The resulting pellet was resuspended in the same buffer and centrifuged at $100000 \times g$ for 60 min to separate microsomal fraction. The granule pellet was lysed in buffer B (1 mM EGTA and $5 \mathrm{mM}$ Hepes, $\mathrm{pH}$ 7.3), homogenized, incubated for $10 \mathrm{~min}$, homogenized again and centrifuged at $48000 \times \mathrm{g}$ for $30 \mathrm{~min}$. The suspension of chromaffin granules was layered on top of a buffer containing 1.6 M sucrose, $1 \mathrm{mM}$ EGTA, $5 \mathrm{mM}$ Hepes, $\mathrm{pH} 7.3$, and centrifuged at $135000 \times \mathrm{g}$ for $60 \mathrm{~min})$. The resulting granules were homogenized again, resuspended in buffer $\mathrm{B}$ and centrifuged at $48000 \times \mathrm{g}$ for $30 \mathrm{~min}$. After homogenization in buffer B, the granules were layered on top of a buffer containing $1 \mathrm{M}$ sucrose, $1 \mathrm{mM}$ EGTA, $5 \mathrm{mM}$ Hepes $\mathrm{pH} 7.3$ and centrifuged at $120000 \times \mathrm{g}$ for $60 \mathrm{~min}$. The granules were then suspended in $10 \mathrm{mM}$ Hepes, $\mathrm{pH} 7.3$, centrifuged at $48000 \times g$ for $30 \mathrm{~min}$ and then resuspended in $10 \mathrm{mM}$ Hepes, $\mathrm{pH}$ 7.3 and $0.3 \mathrm{M} \mathrm{KCl}$, and stored frozen at $-80^{\circ} \mathrm{C}$.

Antibodies and fluorescent markers. Rabbit polyclonal antibody directed against amino-acid residues 1049-1054 of porcine myosin VI heavy chain was from Proteus (USA), rabbit polyclonal antibody directed against human C-terminal region of myosin VI globular tail domain and mouse monoclonal antibody directed against amino-acid residues 291-302 of human myosin VI were from Sigma (USA). Goat polyclonal antibodies against synaptophysin were from Santa Cruz Labo- ratories (USA) and against human calreticulin was a gift from Dr. M. Michalak from the University of Alberta (Canada). Monoclonal antibodies against GM130 and EEA1 were from BD Transduction Laboratories (USA). Monoclonal antibodies against dopamine $\beta$-hydroxylase $(\mathrm{D} \beta \mathrm{H})$ and human clathrin heavy chain were from Santa Cruz Laboratories (USA), and against synapsin were from Synaptic Systems GmbH (Germany). MitoTracker Red CMXRos was from Invitrogen Molecular Probes (USA) and DAPI (4',6-diamidino-2-phenylindole) was from Vector Laboratories (USA). For immunocytochemistry studies, the following secondary antibodies from Molecular Probes were used: goat anti-rabbit IgG labeled with Alexa Fluor 488, goat anti-mouse IgG labeled with Alexa Fluor 546, and donkey anti-goat IgG labeled with Alexa Fluor 546.

Immunoblotting. Proteins from PC12 or bovine adrenal medulla cell fractions were separated using 10\% polyacrylamide/SDS gels and then transferred to a nitrocellulose membrane. After transfer the membrane was blocked for $1 \mathrm{~h}$ at room temperature in TBS (Trisbuffered saline) containing $5 \%$ non-fat milk powder and $0.2 \%$ Triton X-100 followed by 1-hour incubation with appropriate dilutions of different antibodies described above. The primary antibodies were detected using 1:10000 dilutions of anti-rabbit, anti-goat or anti-mouse antibodies conjugated with horseradish peroxidase; the reaction was developed using the ECL method as described by the manufacturer (Pierce, USA). Usually 10$20 \mu \mathrm{g}$ of protein was loaded.

Association of myosin VI with chromaffin granules. Limited proteolysis and stripping experiments were performed to test the character of association of myosin VI with chromaffin granules. Chromaffin granules were incubated with $\alpha$-chymotrypsin $(1: 200$, wt./wt.) for $30 \mathrm{~min}$ at $25^{\circ} \mathrm{C}$ in a buffer containing $0.6 \mathrm{M}$ sucrose and $20 \mathrm{mM}$ Hepes, $\mathrm{pH}$ 7.3. The proteolysis was terminated with $1 \mathrm{mM}$ PMSF, the reaction mixture was separated using $10 \%$ polyacrylamide gels and then subjected to the immunoblot analysis using anti-human myosin VI antibody. For stripping experiment, chromaffin granules were incubated for $30 \mathrm{~min}$ at $25^{\circ} \mathrm{C}$ in the following conditions: (i) in buffer $\mathrm{S}(0.3 \%$ sucrose, $10 \mathrm{mM}$ Hepes, $\mathrm{pH}$ 7.3); (ii) in buffer $\mathrm{S}$ containing additionally $1 \%$ Triton $\mathrm{X}-100$ and $1 \mathrm{M} \mathrm{NaCl}$; (iii) in buffer $\mathrm{S}$ containing additionally $1 \mathrm{M} \mathrm{NaCl}$ and $5 \mathrm{mM}$ ATP; (iv) in buffer S containing additionally 0.6 M KI and $5 \mathrm{mM} \mathrm{ATP;}$ and (v) in buffer $\mathrm{S}$ containing additionally $0.1 \mathrm{M} \mathrm{Na}_{2} \mathrm{CO}_{3}, \mathrm{pH}$ 11.5. The samples were spun at $50000 \times g$, and the presence of myosin VI in the supernatant and pellet fractions was tested by immunoblot analysis using anti-myosin VI antibodies

Analysis of myosin VI splice forms by RT-PCR. To asses expression of myosin VI splice variants in PC12 cells by PCR, total RNA was isolated using RNeasy kit (Qiagen, USA). cDNA was synthesized using M-MLV Reverse Transcriptase (Sigma, USA) with oligo-dT primers (Invitrogen, USA). The following primers flanking the region of the tail containing large insert were used: forward 5'-TCCTGGCCCAGGAGTGCA-3' and reverse 5'-AACTCT'TCTGTGCAAGCAAGCTGC-3'. 'To amplify the region of interest with small insert the following primers were used: forward 5'-GCAGCT'TGCAGAGAAGAAT'T'-3' and reverse 5'-CTGAGGGTCT'T'GTACTGGT-3', according to Dance et al. (2004). PCR fragments were separated on 3\% agarose gels. Individual bands were isolated from the gel using NucleoSpin Extract II (Macherey-Nagel, Germany) and sequenced to identify each splice variant. 
Immunolocalization studies. Distribution of myosin VI and other marker proteins in PC12 or bovine adrenal medulla cells was examined by indirect immunocytochemistry. Cells were fixed in $4 \%$ paraformaldehyde for $30 \mathrm{~min}$ and then permeabilized with $0.1 \%$ Triton X-100 for $5 \mathrm{~min}$. The fixed specimens were thoroughly washed in phosphate-buffered saline (PBS) and treated for 60 min with a $3 \%$ solution of bovine serum albumin (BSA) in PBS. Cells were incubated overnight at $4{ }^{\circ} \mathrm{C}$ with antimyosin VI antibodies at a dilution of $1: 50$. This was followed by incubation with Alexa 488- or Alexa 546-conjugated anti-rabbit secondary antibodies at a dilution of 1:1000 for $60 \mathrm{~min}$. For simultaneous assessment of distribution of other proteins, cells were also incubated with appropriate dilutions of the above described antibodies, and then with Alexa 546- or Alexa 488-conjugated secondary anti-mouse, anti-rabbit or anti-goat antibodies. The specimens were visualized using Leica TCS SP2 spectral confocal microscope equipped with an HCX PL APO $63 \times / 1.25-0.75$ Oil Cs objective.

Visualization of myosin VI and $\mathrm{D} \beta \mathrm{H}$ immunoanalogs on isolated chromaffin granules was performed after attachment of the vesicles to a cover slip coated with Sigmacote (Sigma-Aldrich, USA) followed by blocking the surface for $1 \mathrm{~h}$ at $25^{\circ} \mathrm{C}$ with PBS containing $0.5 \%$ BSA and extensive washes. The staining procedure was as in the case of whole cells, and a Nikon inverted microscope equipped with a Nikon Fluor 100/1.3 objective was used.

\section{RESULTS}

\section{Myosin VI resides on adrenal medulla chromaffin granules}

As presented in Fig. 1a, myosin VI was detected in four different chromaffin granule preparations from bovine adrenal medulla, which confirmed that this attachment was not coincidental. Neither myosin IB nor IIB, known to be expressed in chromaffin cells, were found in the preparations.

To test the nature of the association of myosin VI with the granules, chymotryptic digestion of a chromaffin granule preparation was performed that revealed accumulation of the C-terminal about $50-\mathrm{kDa}$ cleavage product (Fig. 1b). The susceptibility of myosin VI heavy chain to the protease indicates that the protein resides on the apical surface of the granule. Also, stripping experiments were performed (Fig. 1c). Myosin VI was completely detached from chromaffin granules only in the presence of a non-ionic detergent, but not in the presence of $\mathrm{NaCl}, \mathrm{KI}$ or high $\mathrm{pH}\left(\mathrm{Na}_{2} \mathrm{CO}_{3}\right)$, suggesting its strong attachment to the granule membrane.

Double staining of a granule preparation with antihuman myosin VI antibody and monoclonal antibody against dopamine $\beta$-hydroxylase $(\mathrm{D} \beta \mathrm{H})$, a marker enzyme of chromaffin granules, demonstrated that both proteins were often present on the same vesicles (Fig. 1d), thus confirming the association of myosin VI with the granules.

\section{Characterization of myosin VI splice variants in PC12 cells}

It is known that in mammalian cells four alternatively spliced myosin VI isoforms can be generated due to the presence of two inserts within the C-terminal globular tail domain, the small and large ones (Fig. 2a). To assess which of the myosin VI splice variants were expressed (a)

(b)

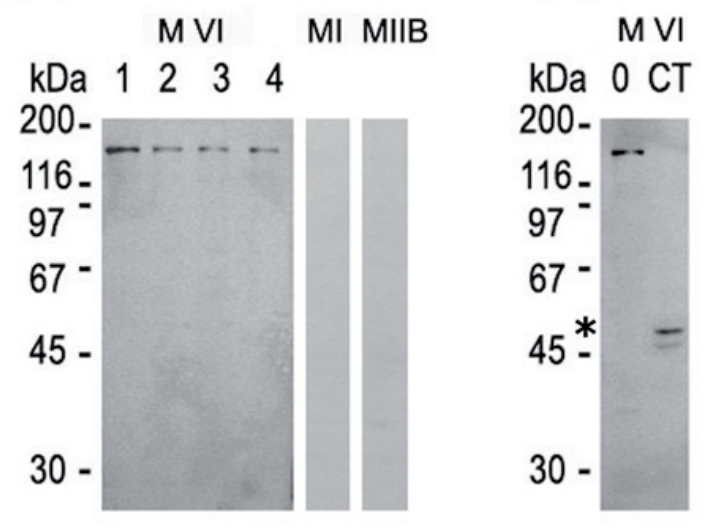

(c)

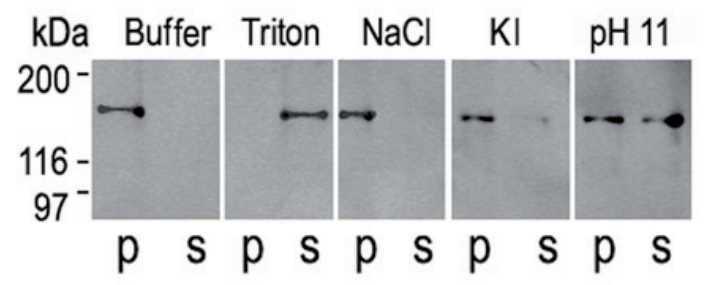

(d)

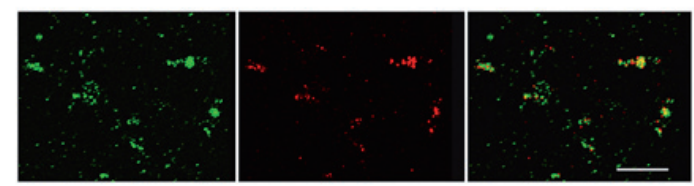

Figure 1. Association of myosin VI with chromaffin granules (a) detection of myosin $\mathrm{VI}$ in several granule preparations (lanes 1-4), lanes 5 and $6-$ probing for myosins IB and IIB, respectively; (b) chymotryptic cleavage of granules produces about $50 \mathrm{kDa}$ C-terminal myosin VI degradation product; (c) stripping of myosin $\mathrm{VI}$ from granule surface was performed with $1 \%$ Triton $\mathrm{X}-100,1 \mathrm{M}$ $\mathrm{NaCl}, 0.6 \mathrm{M} \mathrm{KI}$ or $0.1 \mathrm{M} \mathrm{Na}_{2} \mathrm{CO}_{3}(\mathrm{pH} 11.5)$, as indicated. Presence of myosin $\mathrm{VI}$ in pellet $(\mathrm{p})$ and supernatant $(\mathrm{s})$ fractions was revealed using anti-human myosin VI antibody, protein concentration was about $1 \mathrm{mg} / \mathrm{ml}$ and usually $10-20 \mu \mathrm{g}$ of protein was loaded onto the gel; (d) myosin VI (in red) and dopamine $\beta$-hydroxylase (in green) reside on the same chromaffin granules. Images were obtained with a Nikon inverted microscope equipped with a 100x objective. Bar, $10 \mu \mathrm{m}$.

in PC12 cells, RT-PCR technique was employed. As presented in Fig. 2b, a band with the small insert was easily seen while a band containing the large insert was barely detected.

\section{Subcellular distribution of myosin VI in chromaffin cells}

Cellular localization of myosin VI was examined in rat pheochromocytoma PC12 cells, an established model of adrenal medulla chromaffin cells (Trifaro, 2002; Martin \& Grishanin, 2003). Double staining was performed using antibodies against myosin VI and proteins known to be markers of chromaffin and synaptic granules such as the above-mentioned $\mathrm{D} \beta \mathrm{H}$, synaptophysin and synapsin (Fig. 3a). As seen, myosin VI was associated with various punctate structures scattered throughout the entire cell but only a subset of them corresponded to secretory granules. 
(a)

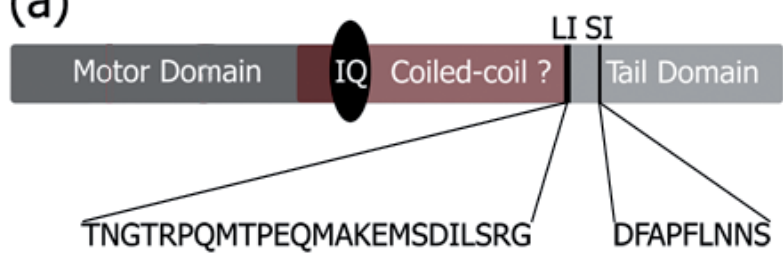

(b)

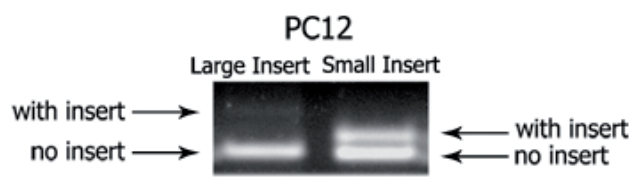

Figure 2. Assessment of myosin VI splice variants

(a) diagram presenting sequence and position of inserts in C-terminal tail domain of rat myosin VI heavy chain; (b) RT-PCR products obtained with primers designed to produce fragments containing either small or large inserts, as indicated in (a).

Therefore a question arose as to the identity of the other cell compartments with which myosin VI was associated. To address this problem, a series of double stainings were performed (Fig. 3b) with specific markers of subcellular compartments: the Golgi apparatus (antibody against GM130, a protein associated with Golgi cis-compartment), endoplasmic reticulum (antibody against calreticulin), early endosomes (antibody against EEA1), clathrin-coated vesicles (antibody against clathrin), mitochondria (Mitotracker), and nuclei (DAPI). Only occasional colocalization of myosin VI with mitochondria and early endosome markers was observed but evident co-staining with the cis-Golgi marker and profound colocalization with clathrincoated vesicles and the endoplasmic reticulum.

Interestingly, double staining with DAPI revealed a significant pool of myosin VI scattered as puncti within the nucleus, in chromatin-free regions. The nuclear localization of myosin VI was confirmed with all three anti-myosin VI antibodies used in the studies, i.e. monoclonal and two polyclonal antibodies ones - anti-human and anti-porcine (Fig. 4b); it was also observed in a bovine adrenal medulla primary cell culture (Fig. 4a).

\section{DISCUSSION}

We assessed the association of myosin VI with chromaffin granules as well as its subcellular distribution and

(a)

(b)
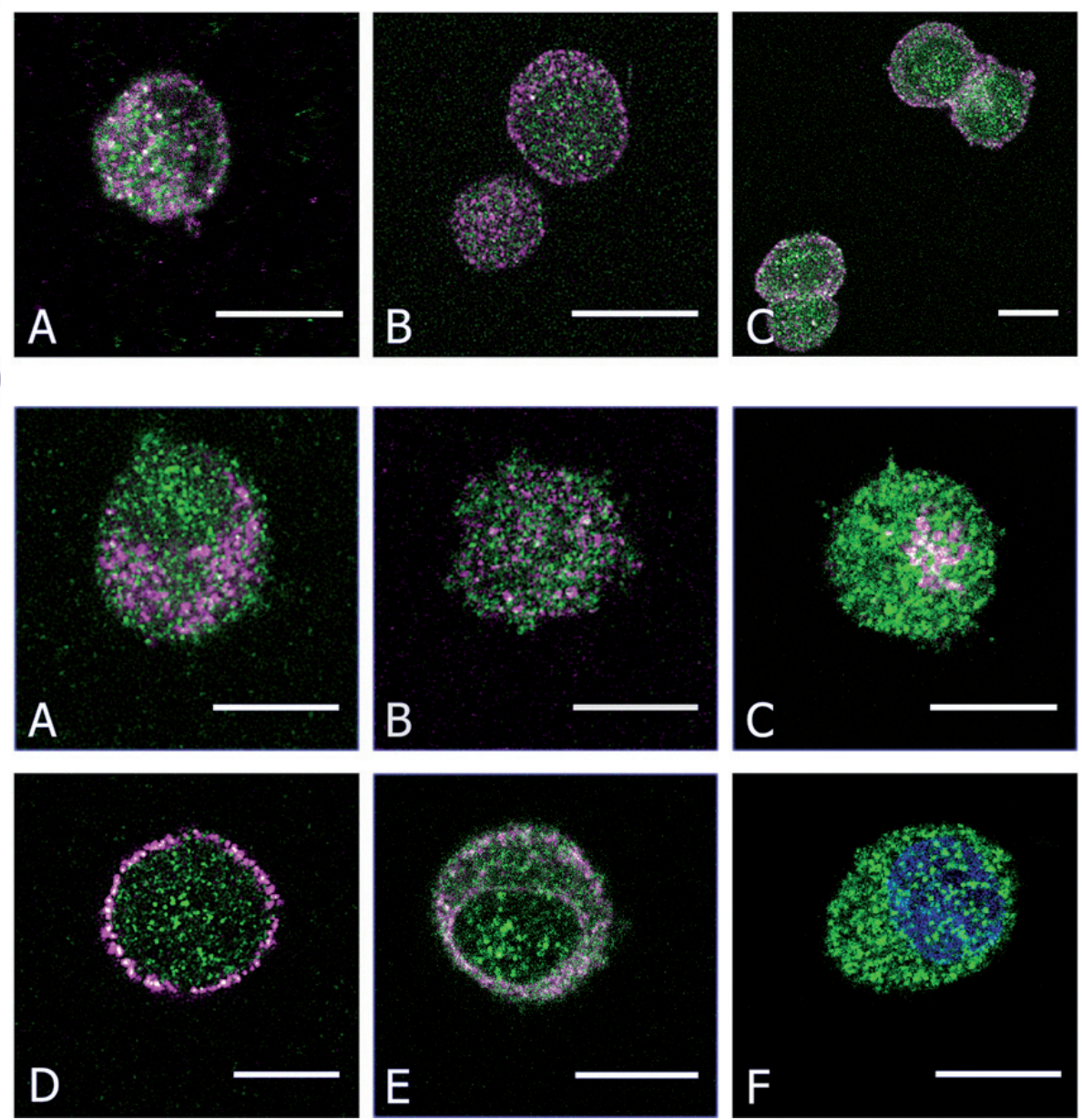

Figure 3. Distribution of myosin $\mathrm{VI}$ in $\mathrm{PC} 12$ cells

(a), partial colocalization of myosin VI (in green) with chromaffin granule markers: A, dopamine $\beta$-hydroxylase, B, synaptophysin and C, synapsin, visualized in magenta; (b), localization of myosin $\mathrm{VI}$ (in green) in subcellular compartments defined by specific markers: A, Mitotracker - mitochondria (in magenta); B, EEA1 - early endosomes (in magenta), C, GM130 - Golgi (in magenta), D, clathrin - clathrin coated pits (in magenta); E, calreticulin - endoplasmic reticulum (in magenta); D, DAPI — nucleus (in blue). The 0.8- $\mu \mathrm{m}$ images of cell center were obtained with a Leica confocal microscope. Bars, $10 \mu \mathrm{m}$. 

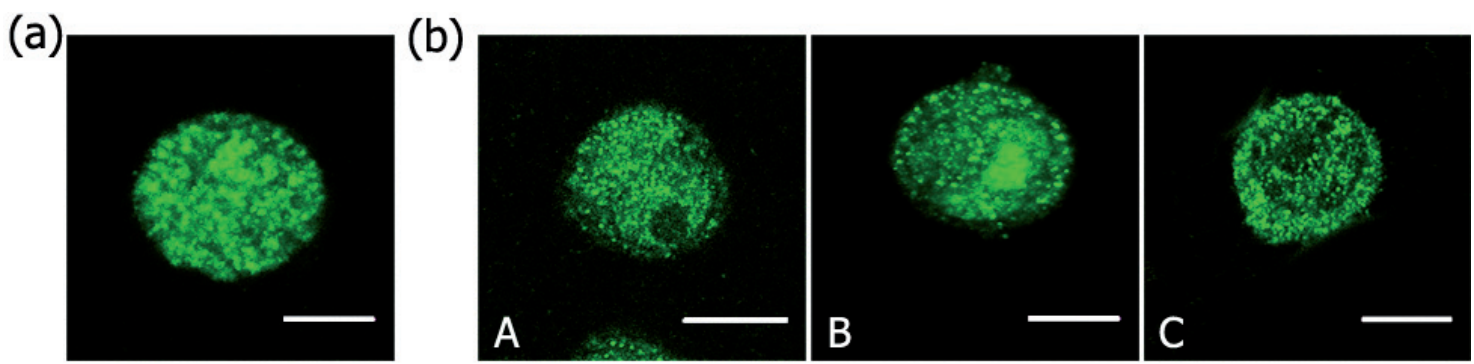

Figure 4. Myosin VI in adrenal medulla and PC12 cells

(a) myosin VI distribution in chromaffin cells cultured from bovine adrenal medulla; (b) myosin VI distribution in PC12 cells demonstrated with three different antibodies: A, anti-human myosin monoclonal antibody, B, anti-human myosin polyclonal antibody, C, anti-porcine myosin polyclonal antibody. These are the 0.8- $\mu \mathrm{m}$ images of cell center obtained with Leica confocal microscope. Bars, $10 \mu \mathrm{m}$.

expression pattern in PC12 cells, a well-characterized model of adrenal medulla chromaffin cells that are homologous to sympathetic neurons.

Myosin VI was strongly attached to the apical surface of chromaffin granules isolated from bovine adrenal medulla and found to reside on the granules together with their marker protein, dopamine $\beta$-hydroxylase $(\mathrm{D} \beta \mathrm{H})$. The observed tight association of myosin VI with the granules indicates a possibility of direct interaction of the tail domain with the granule membrane and an involvement of this unique motor in granule trafficking. Notably, myosins IB and IIB, known to be expressed in PC12 cells (Wagner et al., 1992; Rose et al., 2003), were not bound to the granules. Immunostaining of PC12 cells confirmed the association of myosin VI with chromaffin and secretory granules. It also revealed its distribution in other cell compartments such as the Golgi apparatus, clathrin-coated vesicles and endoplasmic reticulum, which was also observed in other cell types (see Sweeney \& Houdusse, 2007; Buss \& Kendrick-Jones, 2008). Interestingly, we also found myosin VI scattered in chromatin-free regions of the nucleus. A nuclear localization of myosin VI was observed earlier in epithelium-derived carcinoma cell lines: prostate and lung cancer (Jung et al., 2006; Vreugde et al., 2006).

A search for individual splice variants formed in PC12 cells resulted in the finding that the isoforms with the large insert (LI), which in rat myosin VI heavy chain might contain 24 amino acids (based on the rat heavy chain sequence XM_236444 deposited in the GenBank data base), were the minor ones, whereas two other isoforms, i.e. with or without the small insert (SI) were the major ones. The LI variants are known to be expressed mainly in the apical domain of polarized epithelial cells where they participate in targeting to clathrin-coated vesicles through the interaction with Dab2 (Aschenbrenner et al., 2003; Au et al., 2007). Hence, it is not surprising that the LI isoform is underrepresented in PC12 cells that in undifferentiating conditions do not reveal polarity. The SI form is postulated to be involved in basolateral sorting (Morris et al., 2002; Au et al., 2007). The compartmental localization of myosin VI splice variants observed in retinal pigmented epithelial cells also revealed that the SI and LI isoforms might transport the vesicles through actin network untill they fuse with early endosomes (Aschenbrenner et al., 2003). The presence of a pool of myosin VI associated with clathrin and early endosomes indicates that also in PC12 cells it may be engaged in endocytosis-related processes.

The nuclear localization of myosin VI in PC12 cells, which have to continuously rebuild their resources be- cause of their extremely high turnover of the membrane and various particles associated with stimulation-dependent secretion, was consistently observed with the use of three different types antibodies. Taking into account the cargo-binding activity of myosin VI and its presence in chromatin-free regions of the nucleus it is plausible that myosin VI may play a role of a motor delivering cargo to the nucleus and/or be engaged in trafficking within the nucleus. So far there are no data to support these hypotheses, however, the studies on the nuclear isoform of myosin IC (NMI), clearly showing its involvement in these processes, seem to strengthen them (Chuang et al., 2006; Grummt et al., 2006).

In summary, our studies on the expression and localization of myosin VI in the highly secretory adrenal medulla cells indicate that it serves as a motor engaged in chromaffin granule transport within the cytoplasm and also open the discussion on its possible involvement in nucleo-cytoplasmic trafficking. Further experiments are necessary to dissect its role in adrenal medulla chromaffin cells.

\section{Acknowledgements}

We would like to thank Professor Cristos Stournaras from the University of Crete (Greece) for PC12 cells, Professor Marek Michalak from the University of Edmonton (Canada) for anti-calreticulin antibody. Professor Adam Szewczyk and Dr. Renata Hordejuk from the Nencki Institute are greatly acknowledged for their invaluable help in adrenal medulla granule and primary cell culture preparation.

This work was supported by grant 2 P04C 03728 and the statutory grant to the Nencki Institute from the Ministry of Science and Higher Education as well as by the Polish Network for Mechanisms of Cell Motility.

\section{REFERENCES}

Ameen N, Apodaca G (2007) Defective CFTR apical endocytosis and enterocyte brush border in myosin VI-deficient mice. Traffic 8: 9981006

Aschenbrenner L, Lee TT, Hasson T (2003) Myo6 facilitates the translocation of endocytic vesicles from cell peripheries. Mol Biol Cell 14: 2728-2743.

Au JS-Y, Puri C, Ihrke G, Kendrick-Jones J, Buss F (2007) Myosin VI is required for sorting of AP-1B-dependent cargo to the basolateral domain in polarized MDCK cells. I Cell Biol 177: 103-114.

Bader MF, Holz RW, Kumakura K, Vitale N (2002) Exocytosis: the chromaffin cell as a model system. Ann NY Acad Sci 971: 178-183.

Brocklehurst KW, Pollard HB (1990) Cell biology of secretion. In: Peptide hormone secretion. A practical approach. Hutton JC, Siddle K, eds, pp 233-255. IRL Oxford, New York, Tokyo. 
Buss F, Kendrick-Jones J (2008) How are the cellular functions of myosin VI regulated within the cell. Biochem Biophys Res Commun 369: 165-175.

Buss F, Luzio JP, Kendrick-Jones J (2002) Myosin VI, an actin motor for membrane traffic and cell migration. Traffic 3: 851-858.

Chuang CH, Carpenter AE, Fuchsova B, Johnson T, de Lanerolle P, Belmont AS (2006) Long-range directional movement of an interphase chromosome cite. Curr Biol 16: 825-831.

Dance AL, Miller M, Seragaki S, Aryal P, White B, Aschenbrenner L, Hasson T (2004) Regulation of myosin-VI targeting to endocytic compartments. Traffic 5: 798-813.

Foth BJ, Goedecke MC, Soldati D (2006) New insights into myosin evolution and classification. Proc Natl Acad Sci USA 103: 6681-6686.

Greene LA, Tischler AS (1976) Establishment of a noradrenergic clonal line of rat adrenal pheochromocytoma cells which respond to nerve growth factor. Proc Natl Acad Sci USA 73: 2424-2528.

Grummt I (2006) Actin and myosin as transcrption factors. Genes Dev 17: $1691-1702$

Hook V, Metz-Boutigue MH (2002) Protein trafficking to chromaffin granules and proteolytic processing within regulated secretory vesicles of neuroendocrine chromaffin cells. Ann NY Acad Sci 971: 397-405.

Jung EJ, Liu G, Zhou W, Chen X (2006) Myosin VI is a mediator of the p53 cell survival pathway. Mol Cell Biol 26: 2175-2186.

Martin TFJ, Grishanin RN (2003) PC12 cells as a model for studies of regulated secretion in neuronal and endocrine cells. Methods Cell Biol 71: 267-286.

Mermall V, McNally JG, Miller KG (1994) Transport of cytoplasmic particles catalysed by an unconventional myosin in living Drosophila embryos. Nature 369: 560-562.

Morris SM, Arden SD, Roberts RC, Kendrick-Jones J, Cooper JA, Luzio JP, Buss F (2002) Myosin VI binds to and localises with Dab2, potentially linking receptor-mediated endocytosis and the actin cytoskeleton. Traffic 3: 331-341.

Nagy G, Matti U, Nehring RB, Binz T, Rettig J, Neher E, Sorensen JB (2002) Protein kinase C-dependent phosphorylation of synaptosome-associated protein of $25 \mathrm{kDa}$ at $\operatorname{Ser}^{187}$ potentiates vesicle recruitment. J Neurosci 22: 9278-9286.

Neco P, Giner D, Viniegra S, Borges R, Villarroel A, Gutierrez LM (2004) New roles of myosin II during vesicle transport and fusion in chromaffin cells. J Biol Chem 279: 27450-27457.

Osterweil E, Wells DG, Mooseker MS (2005) A role for myosin VI in postsynaptic structure and glutamate receptor endocytosis. J Cell Biol 168: 329-338.
Redowicz MJ (2002) Myosins and pathology: genetics and biology. Acta Biochim Pol 49: 789-804.

Richards TA, Cavalier-Smith T (2005) Myosin domain evolution and the primary divergence of eukaryotes. Nature 436: 1113-1118.

Rose SD, Lejen T, Casaletti L, Larson RE, Pene TD, Trifaro JM (2003) Myosins II and V in chromaffin cells: myosin V is a chromaffin vesicle molecular motor involved in secretion. I Neurochem 85: 287-298.

Rose SD, Lejen T, Casaletti L, Larson RE, Pene TD, Trifaro JM (2002) Molecular motors involved in chromaffin cell secretion. Ann NY Acad Sci 971: 222-231.

Rudolf R, Kogel T, Kuznetsov SA, Salm T, Schlicker O, Hellwig A, Hammer JA 3rd, Gerdes HH (2003) Myosin Va facilitates the distribution of secretory granules in the F-actin rich cortex of PC12 cells. J Cell Sci 116: 1339-1348.

Spudich G, Chibalina MV, Au JS, Arden SD, Buss F, Kendrick-Jones J (2007) Myosin VI targeting to clathrin-coated structures and dimerization is mediated by binding to Disabled-2 and PtdIns $(4,5) \mathrm{P} 2$. Nature Cell Biol 9: 176-183.

Sweeney HL, Houdusse A (2007) What can myosin VI do in cells? Curr Opin Cell Biol 19: 57-66.

Trifaro JM (2002) Molecular biology of the chromaffin cell. Ann NY Acad Sci 97: 111-118.

Vreugde S, Ferrai C, Miluzio A, Hauben E, Marchisio PC, Crippa MP, Bussi M, Biffo S (2006) Nuclear myosin VI enhances RNA polymerase II-dependent transcription. Mol Cell 23: 749-755.

Wagner MC, Baryłko B, Albanesi JP (1992) Tissue distribution and subcellular localization of mammalian myosin I. J Cell Biol 119: 163-170.

Warner CL, Stewart A, Luzio JP, Steel KP, Libby RT, Kendrick-Jones J, Buss F (2003) Loss of myosin VI reduces secretion and the size of the Golgi in fibroblasts from Snell's waltzer mice. EMBO J 22: 569-579.

Wells AL, Lin AW, Chen LQ, Safer D, Cain SM, Hasson T, Carragher BO, Milligan RA, Sweeney HL (1999) Myosin VI is an actin-based motor that moves backwards. Nature 401: 505-508.

Wu H, Nash JE, Zamorano P, Garner CC (2002) Interaction of SAP97 with minus-end-directed actin motor myosin VI: implications for AMPA receptor trafficking. J Biol Chem 277: 30928-30934.

Yano H, Ninan I, Zhang H, Milner TA, Arancio O, Chao MV (2006) BDNF-mediated neurotransmission relies on upon a myosin VI motor complex. Nature Neurosci 9: 1009-1018. 